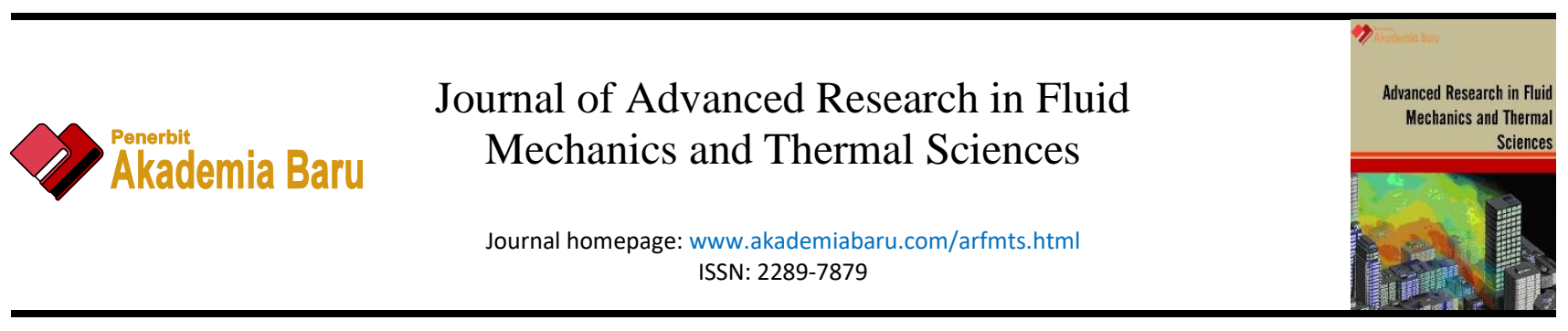

\title{
Application of Computational Fluid Dynamic Simulation for The Study of Heat Stress and Heat Strain - A Review
}

Ahmad Rasdan Ismail ${ }^{1,2}$, Norfadzilah Jusoh ${ }^{1, *}$, Raemy Md Zein ${ }^{3}$, Ismail Abdul Rahman ${ }^{3}$, Mohd Amin Mahd Asri ${ }^{1}$, Nor Kamilah Makhtar ${ }^{4}$

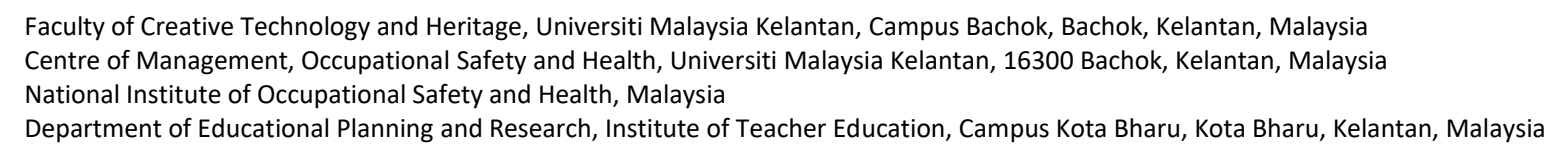

\section{Article history:}

Received 3 March 2020

Received in revised form 11 May 2020

Accepted 11 May 2020

Available online 31 July 2020

\begin{abstract}
The study on heat stress and heat strain has been conducted since early 20th century. However, in the current years, it attracts an increase of attention around the world mainly due to the global climate change issues. Traditionally, there are two main approaches in the study of heat stress and heat strain which are the climatic chamber studies and the field studies. But, with the recent development in the computational fluid dynamic (CFD) simulation, the researchers shift toward this approach as a new method for the study of heat stress and heat strain. Climatic chamber can be simulated with various environmental parameters such as air flow and heat transfer while a manikin is used to identify the effects of these parameters. In this study, recent developments of the CFD simulation for the study of heat stress and heat strain for indoor environment are reviewed while their methodology and results are compared. The discussions that will be presented in this work will focus on the various CFD techniques and its significance as a new method for the study of heat stress and heat strain.
\end{abstract}

\section{Keywords:}

heat stress; thermal comfort; CFD

\section{Introduction}

Heat is a form of energy passes from higher temperature to lower temperature [1]. It can be generated either endogenous or exogenous process [2]. Heat stress is considered a major problem among manufacturing or construction workers not only in Malaysia but also worldwide. Heat stress condition increase in extreme high of temperature and humidity, exposure to high radiant heat, high temperature or humidity occur in combination with heavy protective clothing or higher work rate [3]. The environmental heat stress and the combination of physical work cause heat strain among industrial workers. Environmental heat stress increases the sweat rate, core body temperature and

\footnotetext{
* Corresponding author.

E-mail address: fadzilah.j@umk.edu.my
}

https://doi.org/10.37934/arfmts.73.2.138145 
pulse rate among the employees exposed to heat [4]. Heat Stress is the net heat load to which a worker is exposed from the combination of factors; metabolic heat, environmental factors, and clothing which lead to an increase in bodily heat storage [5]. This will lead to heat strain which is defined as the inability to maintain body core temperature at the level imposed by human thermoregulatory system [6]. Workers are potentially exposed to heat will facing heat stress symptoms if they are not properly protected. Furthermore, industrial workers are easier to expose to discomfort and pain during work [7].

The global climate change leads to the increase of heat exposure on human whether in outdoor or in indoor the environment. Malaysia which has a hot and humid tropical weather would be influenced by this issue more than others countries at North and South of the earth's hemisphere, where they only endure hot temperature during summer which occurs only around three months throughout the year.

The study on the impacts of the working environment on the workers are dominated by most Western scholars [8]. But there is still a lack of awareness of this issue in Malaysia even though there is already an enactment which aims to promote good occupational environment for persons at work [9].

There are many factors that influence the level of heat exposure depends on whether the individual is indoors with or without air-cooling, outdoor in shade or in full sun. The duration of exposure, acclimatization, the level and type of activity and clothing also determine the effect of heat exposure [10]. To understand the influence of each of these factors, scientists or researchers have developed several heat stress and heat strain indexes based on two approaches: the climatic chamber studies and the field studies.

Climatic chamber studies aim to determine steady-state models which are the production of the desired environment conditions (radiant temperature, air temperature, relative humidity and air velocity) and at the same time, the unwanted variables can be controlled to avoid any influence on the results. This type of study is done in a climate simulation chamber which can fit human subjects for experimental purposes [11].

The ability of climatic chamber to control temperature and humidity lead us to the concept of stability. The human thermal response is linked to the environment exposure and is continually adapting to it. When the objective of an experiment is to see exactly how the cognitive and physical factors change according to a specific environment, it is fundamental to assure the stability of the system.

To define the system stability is not enough to ensure steady state conditions of temperature and humidity. It is also very important to assure that all environmental parameters that influence human cognitive, physical and physiological responses are under control.

While, field studies are used in order to study heat stress in the real world. Field studies involve collecting data outside of an experimental. This type of data collection is most often done in natural settings or environments and can be done in a variety of ways for various disciplines. Field studies are known to be expensive and timely; however, the amount and diversity of the data collected can be invaluable. In heat stress and heat strain study, the subjects can conduct their normal daily work without any attempt to control the environment factors [12]. Thus, this kind of study can be easily influenced by other indirect factors such as cultural and psychological factors [13].

\subsection{Problem Statement}

$\mathrm{Hu}$ [14] stated that computational fluid dynamics (CFD) is a science that, with the help of digital computers, produces quantitative predictions of fluid-flow phenomena based on the conservation 
laws (conservation of mass, momentum, and energy) governing fluid motion. These predictions normally occur under those conditions defined in terms of flow geometry, the physical properties of a fluid, and the boundary and initial conditions of a flow field. Such predictions generally concern sets of values of the flow variables, for example, velocity, pressure, or temperature at selected locations in the domain and for selected times. The predictions may also involve evaluations of overall flow behavior, such as the flow rate or the hydrodynamic force acting on an object in the flow.

As a consequence of the advancement in the computing technology, many researchers use the CFD technique for the study of thermal comfort or heat stress for more complex system. At the same time, the use of CFD is increasing widely in many fields of science and engineering. In the past two decades, CFD has shown a wide variety of applications in the field of aerospace and energy [15]. Most of the researchers use the abbreviation CFD and define it as a branch of fluid mechanics that solves and analyses fluid flow problems, using numerical methods and algorithms [16].

For the study of indoor thermal and airflow, CFD is used to numerically model physical processes occurring within a fluid by which mostly intend to solve Navier-Stokes equations. Navier-Stokes equations are the expression of the fundamental physical laws of a control volume of fluid which are the conservation of mass, momentum and thermal energy [17].

In most of the cases where CFD is used, there are previous validations for the modelling methodologies which usually taken from field studies and previous study or the data used to operate the system designed by CFD can be easily obtained. However, there is an increase of the usage of this technique because of the facility of knowledge transfer and the advancement of computational resources from academia, which include software and hardware developers [16].

Heat stress poses a substantial risk to industry workers worldwide in a changing climate. As construction workers comprise an increasingly large and critical part of the global economy, special attention needs to be paid to the risks faced by the global industry workforce from occupational heat stress. Most recent studies on the ergonomics environment focus on the performance of the workers in the term of the productivity [10]. However, they don't approach the problem in the term of human physiology which is normally used in the study of sport science. Furthermore, some studies used quantitative method to identify the effect of the environmental factors on the physiology factors as single study without a relation with the human performance at the workplace.

In this study, recent developments of the CFD simulation for the study of heat stress and heat strain for indoor environment are reviewed while their methodology and results are compared. This is because, $\mathrm{Hu}$ [5] highlights the CFD has a number of distinct advantages. There are: it can be produced inexpensively and quickly, it generates complete information, it allows easy parameter changes, it has the ability to simulate realistic conditions, and it has the ability to simulate ideal conditions.

\section{Method}

This review was conducted primarily using common databases that were searched included PubMed, ScienceDirect, Scopus, references of relevant peer-reviewed literature, and web-based searches (including Google Scholar and documents published by occupational-health organizations). Key words and phrases that were used to search the databases included "heat stress," "heat strain," "evaluation index," "hyperthermal environments," "CFD," "heat acclimation," "heat acclimatization," and thermal comfort. The author mainly focused on CFD in the chamber experimental studies and field studies about heat stress and heat strain in the industry. 


\section{Discussion}

\subsection{Environment Model}

The indoor environment simulated varied from a simple closed chamber to a three level atrium which are usually designed to study the thermal condition of these environments. Morsy et al., [18] used CFD to compare the relation between the insulation materials and thermal comfort in the building. They stimulated educational buildings to study the effect of different thermal insulation materials types and thicknesses on the thermal comfort for the building envelope. The results shows that fourth floor and ground floor need a thick layer of insulation to achieve the needed target while in first, second, and third floor it will be enough to use thin layer of insulation to achieve its optimum thermal comfort and energy consumption.

Kamar et al., [19] simulated a model of a double storey residential house with three rooms mainly, the hall, the upper hall and the kitchen. They simulated a solar chimney which is a natural-draft device for passive cooling as square-shaped openings on the roof at the middle and gable vents by introducing thin rectangular-shaped openings in the walls of the house.

A CFD model of an underground shelter was studied by Mukhtar et al., [20]. In this study, they simulated a model of an underground shelter with passive ventilation by a supply duct and an exhaust duct which take the form of cylindrical tubes. Furthermore, a heating cable which replicates the heat release by the occupants is simulated by a flat rectangle. They claimed that the model suggested was validated by the data measured from previous study.

Jusoh et al., [21] studied the thermal building in a non-uniform thermal environment. In their study, they simulated a workplace ergonomic simulator chamber which was a very small chamber with the size of $3.6 \mathrm{~m} \times 2.4 \mathrm{~m} \times 2.4 \mathrm{~m}$. A small rectangular box was made on the top inside the chamber which replicated the air-condition unit of an office. However, no obstacles, such as furniture were introduced into the CFD chamber which simplifies the real situation in the office environment.

CFD simulation was also used for the study of hospital environment. In a heat related study, Kamsah et al., [22] simulated a model of an operating room (OR) which incorporated with a vertical air supply system and four horizontal outlet grilles. The model consisted of an operating table, an air inlet diffuser, four air exhaust grilles, four medical staffs and two surgical lamps.

In a study of heat transfer and physiological responses of unclothed human body in hot environment, Yang et al., [23] designed a simulation model of a simple 3D climate chamber with length, width and height of $5 \mathrm{~m}, 3 \mathrm{~m}$, and $2.7 \mathrm{~m}$, respectively. Another study simply used a 2D room $4 \mathrm{~m} \times 3 \mathrm{~m}$ to investigate thermal sensation of occupants using a thermophysiological model [24]. The air conditioner was included in the model with the air supply entrance on the top-left and the exit on the bottom-right.

Pérez et al., [25] simulated an engine room of a ship which reproduces the real navigation conditions in tropical regions, with two main engines working, to predict indoor conditions. Tsai [26] developed a CFD model of an offshore platform by simulating a domain of boarding riser skid which has a dimension of $50 \mathrm{ft} \times 50 \mathrm{ft} \times 25 \mathrm{ft}$. All the equipment and processing unit were modelled and incorporated with the model of boarding riser skid. Sugiono et al., [27] studied the thermal comfort of workers in the finished good warehouse. Thus, they proposed a model of a warehouse with an area of $2450 \mathrm{~m}^{2}$ with the head of $7 \mathrm{~m}$ which consists of 2 main sections. Section 1 with $1400 \mathrm{~m}^{2}$ area, while section 2 with $1050 \mathrm{~m}^{2}$ area.

There was another study which focuses on the effects of the double-glazed window with curtains on thermal condition. In the study, a simple bedroom chamber was simulated with length, width and height of $3 \mathrm{~m}, 3 \mathrm{~m}$, and $3 \mathrm{~m}$, respectively which oriented towards south. However, they put in place several obstacles such as desk, heat collector, light, person and bed which represent by 3D blocks 
with different size [28]. Abdullah and Wang [29] simulated the top-lit three-storey Malaysian atrium. They used a complex model with several doors, windows, and floor balcony and corridor areas as well. It was incorporated with fully glazed pitched roof top and void areas within the central atrium.

\subsection{Heat Stress Index}

Various heat stress index was used in the previous study to investigate the thermal environmental. Abdullah and Wang [29] used 'Predicted Mean Vote' (PMV) index to study the environment of an atrium. The software computed the air temperature, radiant temperature and air velocity, while the PMV index was computed by setting the individual parameter (Clo-value and metabolic rate) as well as the relative humidity which is an additional environmental parameter.

Jusoh et al., [21] used the combination of Predicted Mean Vote-Predicted Percentage of Dissatisfied (PMV-PPD) introduced by Fanger [30]. PPD can be derived from the PMV according ISO7730. The index which was presented used a fix activity level of 1 Met and a level of clothing insulation of $0.5 \mathrm{Clo}$. Zhang et al., [28] and Sugiono et al., [27] also used the same index to study the effect of double-glazed window with curtains on the thermal condition of a CFD model of a bedroom and to study the thermal comfort of warehouse respectively. This is supported by the fact that this index is also used by both the ASHRAE standards of USA and ISO standards for the evaluation of indoor thermal environment.

A multi-node thermal model was developed by Yang et al., [23] to determine thermal responses of the human body with the inputs such as human activity intensity, clothing properties, and environmental conditions. The model has 20 segments of human body corresponding to the manikin Newton, which contain four layers: core, muscle, fat, and skin layer. There are three systems of the model; an active system, a passive system, and a clothing system. The active system simulated human thermoregulation while the passive system predicted the heat exchange within the human body and between human body and the environment.

Kamar et al., [19] only measured the dry-bulb temperature, wet-bulb temperature and relative humidity in their CFD model for double-storey residential house. While Mukhtar et al., [20] simply used dry temperature for their study on the underground shelter model. However, they mentioned about effective temperature when discussing the effect of heat from the occupant towards the thermal environment. Pérez et al., [25] compared the globe temperature and operative temperature of a model of engine room in a ship. They found out that the operative temperature obtained from the CFD can be used, instead of the globe temperature, without loss of precision. Angelova et al., [24] took into account the skin temperature as an evaluation for heat stress for the study of the influence of clothing and activity on the occupants based on CFD simulation.

Tsai [26] proposed a CFD WBGT model using the incident radiation data, ambient temperature and wind speed from the CFD model. He claimed that the WBGT model developed could be used to analyse heat stress with high fidelity and accuracy for many applications in high temperature environments with complex equipment installations.

\subsection{Manikin Model}

Mukhtar et al., [20] simulated the indoor occupants by a 3D model of heating cable which replicates the heat released by the occupants. However, this model was not very appropriate as it neglected the real distribution of heat release by the occupants. Kamsah et al., [22] used standing 3D model of block manikin to simulate the medical staffs and laying 3D model of block manikin for the patient in their study. The model consisted of three parts. A block was for the legs and feet, another 
block was for the body and hand and a smaller block was for the head. Figure 1 shows the 2D representation of the manikin and Table 1 shows the dimensions of the manikin. The limitation of this manikin model was the effects of each human body parts could not be detected. However, this model could be used for simpler and less computational capacity. In their study, the distribution of heat of the manikin was not the focus; therefore, it was not a compulsory to have a perfect manikin for the CFD simulation.

Angelova et al., [24] placed a standing human body manikin in the middle of a 2D simulation room. The shape of the manikin was a simplified version of a previous study by Pichurov [31]. The height of the body was $1.65 \mathrm{~m}$ and its surface area was $1.7 \mathrm{~m}^{2}$. Figure 2 shows the model of manikin used. The 2D model used can shorten the computational time for the simulation but with the cost of the real 3D representation of the thermal flow from the manikin. As in the real life condition, heat which is distributed from the front is not similar from behind the body. However, in a study which focused on the clothing of the manikin, the complex distribution of the bodily heat can be neglected to easily compare the part of the body which were covered and not covered by clothes.

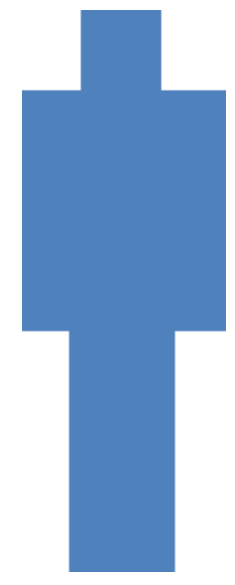

Fig. 1. 2D representation of 3D Manikin proposed by Kamsah et al., [22]

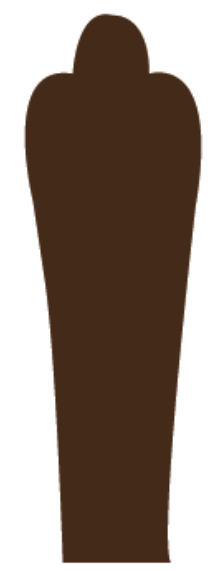

Fig. 2. 2D representation of 2D Manikin proposed by Angelova et al., [24]

Table 1

Dimensions of the manikin [11]

\begin{tabular}{ll}
\hline Model & $\begin{array}{l}\text { Dimensions } \\
(\text { Length }(\mathrm{m}) \times \text { Width }(\mathrm{m}) \times \text { Height }(\mathrm{m}))\end{array}$ \\
\hline Medical staff & \\
-Body & $0.3 \times 0.2 \times 0.6$ \\
-Head & $0.16 \times 0.16 \times 0.30$ \\
-Hand & $0.1 \times 0.2 \times 0.6$ \\
-Leg & $0.3 \times 0.2 \times 0.7$ \\
Patient & \\
-Body & $0.6 \times 0.3 \times 0.2$ \\
-Head & $0.30 \times 0.16 \times 0.16$ \\
-Hand & $0.6 \times 0.1 \times 0.2$ \\
-Leg & $0.7 \times 0.3 \times 0.2$ \\
\hline
\end{tabular}

An advanced manikin was developed by Yang et al., [23] by using a 3D laser scanning technique to obtain the geometrical details of an unclothed 20-zone manikin Newton in a standing position. Then, the surface of the numerical manikin was subdivided into 20 body segments (face, head, upper arms, forearms, hands, chest, shoulder, stomach, back, hips, thighs, calves, and feet) corresponding 
to the manikin Newton by the commercial software ANSYS 14.5. This manikin represented almost perfectly the real human body, but with less detail such as eyes and other smaller organs. In the study, they used the manikin to identify the physiological responses of the unclothed human body in hot environments. Thus, it is necessary to have a perfect manikin which can simulate a general distribution of heat throughout the body especially the skin.

Xu et al., [32] studied the difference between different manikin models. They found out that 2D model can give the approximate air flow distribution in an indoor environment. However, the air flow predictions from 3D model were even closer to the real condition. The simplification of body structure also influenced the total heat transfer from the human body where they compared 'cylinder man' vs 'tin-man' model.

\section{Conclusions}

Computational Fluid Dynamic Simulation (CFD) has a great potential in the research of heat stress or thermal environment. Many previous studies show that CFD could be used to support the findings from the field study or experimental study of heat stress such as the study of residential building, office environment, offshore and industry. Different heat stress indexes were used in the studies depends on the main focus of the study. Human model could be simulated by a manikin which differs for each study which influenced by the heat stress index used in the study. Therefore, to apply the CFD simulation in a heat stress study, these three factors should be decided beforehand; the environment design, heat stress index and manikin model.

\section{Acknowledgement}

This research was funded by a grant from National Institute of Occupational Safety and Health (NIOSH).

\section{References}

[1] Zainal, S., C. Tan, C. J. Sian, and T. J. Siang. "ANSYS simulation for Ag/HEG hybrid nanofluid in turbulent circular pipe." Journal of Advanced Research in Applied Mechanics 23, no. 1 (2016): 20-35.

[2] Simon, Harvey B. "Hyperthermia and heatstroke." Hospital Practice 29, no. 8 (1994): 65-80. https://doi.org/10.1080/21548331.1994.11443062

[3] Daud, Aziah, Edimansyah Abdin, Azwan Aziz, Lin Naing, and Rusli Nordin. "Assessment of indoor air quality and heat stress exposure in an automotive assembly plant." Air Quality (2010): 343-356. https://doi.org/10.5772/9765

[4] Parameswarappa, S., and J. Narayana. "Assessment of Heat Strain Among Workers in Steel Industry a Study." Int J Curr Microbiol App Sci 3, no. 9 (2014): 861-70.

[5] NIOSH. NIOSH: Occupational Exposure to Heat and Hot Environments. In US Department of Health and Human Services, 2016.

[6] Haldane, J. S. "The influence of high air temperatures No. I." Epidemiology \& Infection 5, no. 4 (1905): $494-513$. https://doi.org/10.1017/S0022172400006811

[7] Ahmad Rasdan Ismail, Khairul Azhar Mat Daud, Nik Zulkarnaen Khindzir, Mohd Firuz Mohd Anwar, Mohd Firdaus Mahamad Ali. "Application of Visual Computer Simulation in Industrial Ergonomics." International Journal of Creative Futures and Heritage 2, no. 1 (2014): 1-11.

[8] Jeffrey, E. Fernandez. "Ergonomics in the workplace." Facilities 13, no. 4 (1995): 20-27. https://doi.org/10.1108/02632779510083359

[9] Husein, Torik, M. Kholil, and Ari Sarsono. "Perancangan sistem kerja ergonomis untuk mengurangi tingkat kelelahan." Industrial and Systems Engineering Assessment Journal (INASEA)-Discontinued 10, no. 1 (2009).

[10] Kjellstrom, Tord, David Briggs, Chris Freyberg, Bruno Lemke, Matthias Otto, and Olivia Hyatt. "Heat, human performance, and occupational health: a key issue for the assessment of global climate change impacts." Annual review of public health 37 (2016): 97-112.

https://doi.org/10.1146/annurev-publhealth-032315-021740 
[11] Ismail, Ahmad Rasdan, M.R.A. Rani, Baba Md. Deros, Z. K.M. Makhbul, and Mohd Yusri Mohd Yusof. "Response Surface Method in Modelling the Environmental Factors Toward Workers' Productivity." Journal Occupational Safety \& Health 9 (2012): 83-90.

[12] A.R Ismail, M. R. A. Rani, Z. K. M. Makhbul, M.J.M. Nor, and M.N.A Rahman. "A Study of Relationship Betwwen WBGT and Relative Humidity to Worker Performance. " World Academy Of Science, Engineering And Technology, Volume 39 (2019): 216-21.

[13] Taleghani, Mohammad, Martin Tenpierik, Stanley Kurvers, and Andy Van Den Dobbelsteen. "A review into thermal comfort in buildings." Renewable and Sustainable Energy Reviews 26 (2013): 201-215. https://doi.org/10.1016/i.rser.2013.05.050

[14] Hu, Howard H. "Computational fluid dynamics." In Fluid mechanics, pp. 421-472. Academic Press, 2012. https://doi.org/10.1016/B978-0-12-382100-3.10010-1

[15] Khalil, Essam. E. "CFD history and applications." CFD Letters 4, no. 2 (2012): 43-46.

[16] Raman, Ram Kumar, Yogesh Dewang, and Jitendra Raghuwanshi. "A Review on Applications of Computational Fluid Dynamics." International Journal of LNCT 2, no. 6 (2018): 137-43.

[17] Versteeg, H. K and Malalasekera, W. Introduction to Computational Fluid Dynamics: The Finite Volume Method. Harlow: Longman Scientific and Technical, 1995.

[18] Morsy, M., M. Fahmy, H. Abd Elshakour, and A. M. Belal. "Effect of thermal insulation on building thermal comfort and energy consumption in Egypt." Journal of Advanced Research in Applied Mechanics 43, no. 1 (2018): 8-19.

[19] Kamar, Haslinda Mohamed, Nazri Kamsah, and J. L. Kam. "Indoor air of a double-storey residential house in Malaysia." Journal of Advanced Research in Fluid Mechanics and Thermal Sciences 31, no. 1 (2017): 11-18.

[20] Mukhtar, Azfarizal, Khai Ching Ng, Mohd Zamri Yusoff, Wah Yen Tey, and Lit Ken Tan. "Performance assessment of passive heating and cooling techniques for underground shelter in equatorial climate." Journal of Advanced Research in Fluid Mechanics and Thermal Sciences 61, no. 1 (2019): 20-32.

[21] Jusoh, Norfadzilah, Rosli Abu Bakar, Ahmad Rasdan Ismail, and Tanti Zanariah Shamshir Ali. "Computational analysis of thermal building in a no-uniform thermal environment." Energy Procedia 68 (2015): 438-445.

https://doi.org/10.1016/i.egypro.2015.03.275

[22] Kamsah, Nazri, Haslinda Mohamed Kamar, Muhammad Idrus Alhamid, and Wong Keng Yinn. "Impacts of temperature on airborne particles in a hospital operating room." Journal of Advanced Research in Fluid Mechanics and Thermal Sciences 44, no. 1 (2018): 12-23.

[23] Yang, Jie, Shunjiang Ni, and Wenguo Weng. "Modelling heat transfer and physiological responses of unclothed human body in hot environment by coupling CFD simulation with thermal model." International Journal of Thermal Sciences 120 (2017): 437-445.

https://doi.org/10.1016/j.ijthermalsci.2017.06.028

[24] Angelova, Radostina A., George Pichurov, Iskra Simova, Peter Stankov, and losu Rodrigo. "CFD Based Study of Thermal Sensation of Occupants Using Thermophysiological Model. Part II." International Journal of Clothing Science and Technology 27, no. 1 (2015): 60-74.

https://doi.org/10.1108/IJCST-10-2013-0116

[25] Pérez, José Antonio, José Antonio Orosa, and Teresa Grueiro. "A three-dimensional CFD simulation study to reduce heat stress in ships." Applied Thermal Engineering 94 (2016): 413-421.

https://doi.org/10.1016/j.applthermaleng.2015.11.001

[26] Tsai, Kuochen. "CFD Modeling Of WBGT For An Offshore Platform." In SPE Annual Technical Conference and Exhibition. Society of Petroleum Engineers, 2015.

https://doi.org/10.2118/174963-MS

[27] Sugiono, Sugiono, Rio Prasetyo Lukodono, and Rizky Tiovana. "IMPROVING THERMAL COMFORT OF WORKERS IN THE FINISHED GOOD WAREHOUSE BASED ON PREDICTED MEAN VOTE (PMV) USING COMPUTATIONAL FLUID DYNAMICS (CFD)." IETI Transactions on Ergonomics and Safety 3, no. 1 (2019): 12-24.

[28] Zhang, Yan, Lifei Huang, and Yuanyuan Zhou. "Analysis of indoor thermal comfort of test model building installing double-glazed window with curtains based on CFD." Procedia Engineering 121 (2015): 1990-1997. https://doi.org/10.1016/i.proeng.2015.09.197

[29] Abdullah, Abd Halid, and F. Wang. "Modelling thermal environmental performance in top-lit Malaysian atrium using computational fluid dynamics (CFD)." International Journal of Integrated Engineering 1, no. 2 (2011): 27-42.

[30] Fanger, Poul O. "Thermal comfort. Analysis and applications in environmental engineering." Thermal comfort. Analysis and applications in environmental engineering. (1970).

[31] Pichurov, G. "Gagge Model, Tanabe Model - Integration of CFD." In EuroAcademy on Ventilation and Indoor Climate, Course 5. " CFD Based Design of Indoor Environment, 47-51. Pamporovo, Bulgaria, 2018.

[32] Xu, J., A. Psikuta, S. Annaheim, R. M. Rossi, and J. Li. "2D and 3D Simulation on Thermal Flow Around the HumanBody." In Comsol Conference, 2018. 